\title{
Twelve unidentified skeletons as remains of an epidemic or famine in Northern Finland
}

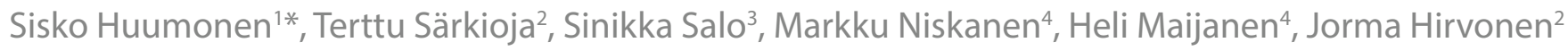

'Institute of Dentistry, University of Turku, 20520 Turku, Finland; Department of Diagnostic Imaging, Turku University Hospital, 20520 Turku, Finland 2Departments of Forensic Medicine, University of Oulu, BOX 8000, Fl-90014 University of Oulu, Finland

${ }^{3}$ Department of Dentistry, University of Oulu, BOX 8000, FI-90014 University of Oulu, Finland

${ }^{4}$ Department of Archeology, University of Oulu, BOX 8000, Fl-90014 University of Oulu, Finland

*Corresponding author e-mail: Sisko.huumonen@utu.fi

\begin{abstract}
:
Skeletal remains of 12 individuals were found in a grave in a tar-burning pit. There were no coffins or other belongings to help with identification or reveal the cause of death.

Methods: Forensic osteological and odontological methods were used to establish sex, age and height. Histological and chemical tests, including the determination of $\mathrm{C}-14$ content, were applied to dating the skeletal remains.

Results: Out of 12 skeletons, 8 were adults; 5 females, 2 males and 1 probable female. Four skeletons belonged to children (ages 1-12 years). The bones had been in the grave for more than 100 years as concluded from the deterioration of the distal parts, embrittling of the surface to $1 \mathrm{~mm}$ depth. C-14 results gave the radiocarbon years $95+/-65 \mathrm{Bp}$ (before present, i.e., 1950). The calibrated years correspond to two time periods, 1670-1780 AD and 1798-1944 AD, as a possible period of death.

Conclusions: Starvation and illnesses are the most plausible explanations for the deaths. Historical studies show that during the $17^{\text {th }}$ and $19^{\text {th }}$ centuries, there were famines in Finland accompanied by severe infections (severe famines in the years 1866-1868 and 16961697), forcing a lot of people to leave their homes.
\end{abstract}

Keywords:

unidentified bodies, historical grave, methodological issues, age estimation, sex estimation, dating skeletal remains

\section{INTRODUCTION}

In the case of historical grave findings, the problems of identification are often compounded by the lack of documents, clothing or other personal belongings. The focus is therefore on the estimation of sex, age and stature.

Determination of sex is crucial for further analysis of unidentified human remains, because many of the methods used for age and stature estimation are sex-specific [1, 2]. The pelvis is the most reliable indicator of sex. Cranial morphology is also used, but since many of the cranial features are size-related, including them in sex estimation requires more experience and familiarity with morphological variation in the entire population than the pelvis [3]. A study has shown that postcranial measurements are better indicators of sex than measurements of the cranium [4].

In general, the development of teeth and the appearance of the ossification centres, epiphyseal union and the length of the long bones are the principal criteria for estimating age at death in children and teenagers. Even if dental development provides the most accurate results, other ageing methods should be employed if possible. Dental development (calcification and eruption of teeth) gives the most accurate age information because it is largely controlled by genetic factors and relatively independent of environmental factors $[5,6]$.

In general, the age estimation for adult individuals is less reliable than that for children and teenagers. While the age estimates for children are based on relatively regular skeletal and dental development, the estimates for adults concentrate on less regular degenerative changes [7].

In spring 1996, excavation work was carried out in an old farm courtyard in Northern Ostrobothnia in a village called Ruukki, which means an "old iron foundry". The excavator dug up pieces of bones which were identified as parts of a human skull. The police were immediately informed and the area was isolated. The grave was investigated by the police, a forensic pathologist and an archaeologist.

The finding aroused great interest in the newspapers and rumours circulated about the origin of the grave; for instance, it was claimed that a clandestine burial of victims of an execution had occurred in 1918 during the Finnish civil war. Due to the great public interest, it was decided that a more thorough investigation than usual should be undertaken.

Moreover, we think that it is important to gain practical experience of the preservation of body remains in ground that is frozen six months a year, a situation that is not encountered in Central Europe.

\section{The aims of the study}

1. To reveal the time, circumstances and cause of this exceptional group burial.

2. To determine the minimum number of individuals and their biological profiles (including sex, age and stature).

3. To determine the causes and manner of death.

\section{MATERIAL AND METHODS}

\section{Observations and actions on the grave and the skeletons at the} finding site

The actual grave was an old tar-burning pit, still containing charcoal pieces within the soil, which also contained sand. The soil layer above the skeletons 
was only half a metre thick (Figure 1). Some small pieces of wood were discovered among the bones. The skeletons and loose bones were lying in two layers (Figure 2). The layers were overlapping. The grave and the bones were photographed while they were being excavated by a forensic pathologist, aided by policemen and an archaeologist. Quite soon it became apparent that the grave was so old that the findings were no longer of interest to the police, and the investigation was continued for archaeological and medical interest only.

The bones were carefully excavated and cleaned, and the number of skeletons was preliminary estimated. The bones, many of which were missing, had disintegrated and the number of bodies was initially set at eleven to twelve. No clothing, belongings or remains of coffins were found in the grave, indicating that the bodies were buried naked.

\section{The final skeletal material}

The bones were sorted and arranged as individuals in the laboratory. The minimum number of individuals in this case was 12 . These individuals represented both sexes and a wide age range from children to older adults. The preservation of the remains varied. Generally, most of the adult individuals had the main skeletal elements such as cranium, os coxae and long bones present. However, these elements were not necessarily complete

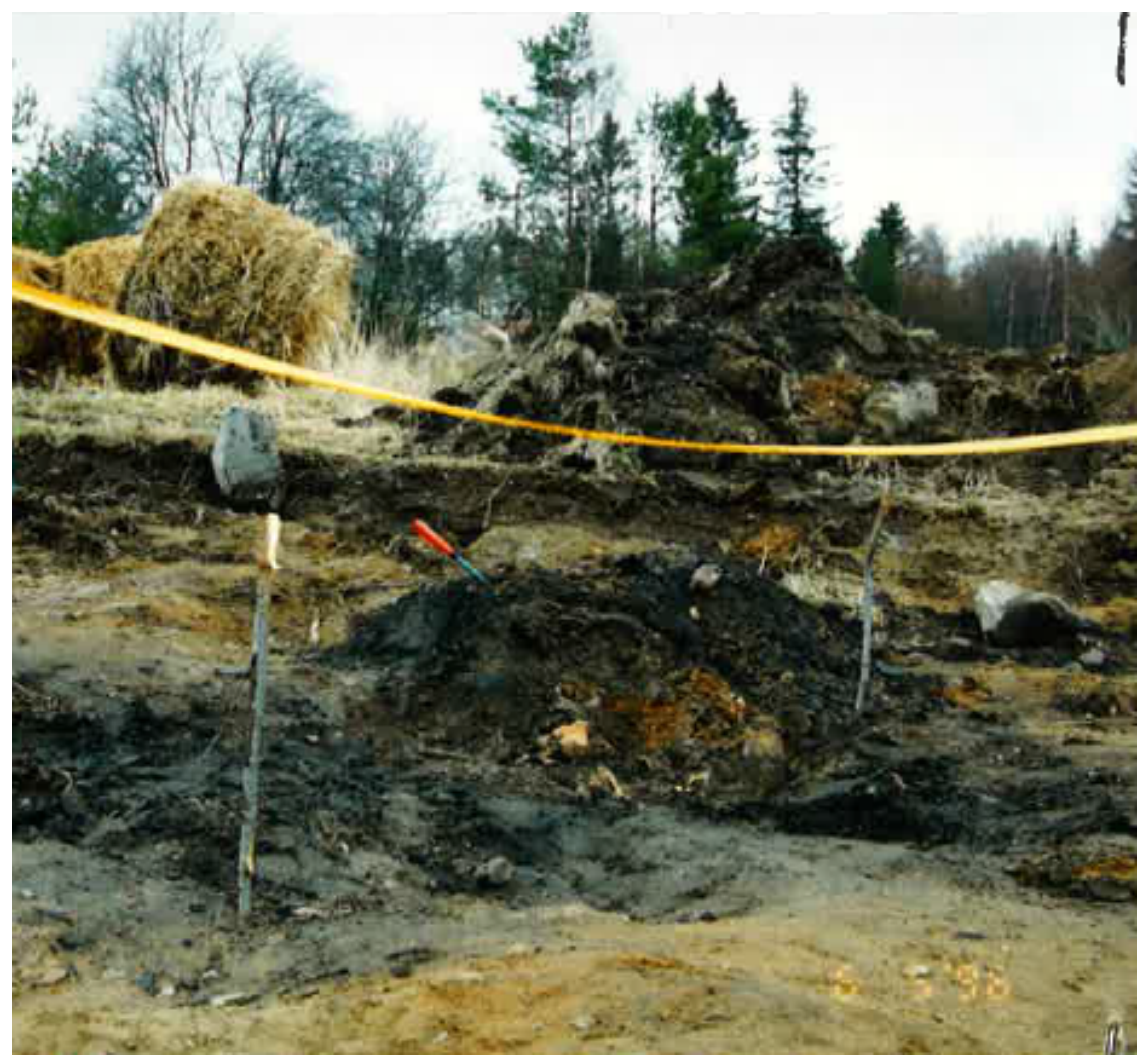

Figure 1. The soil layer above the skeletons was only half a meter thick.

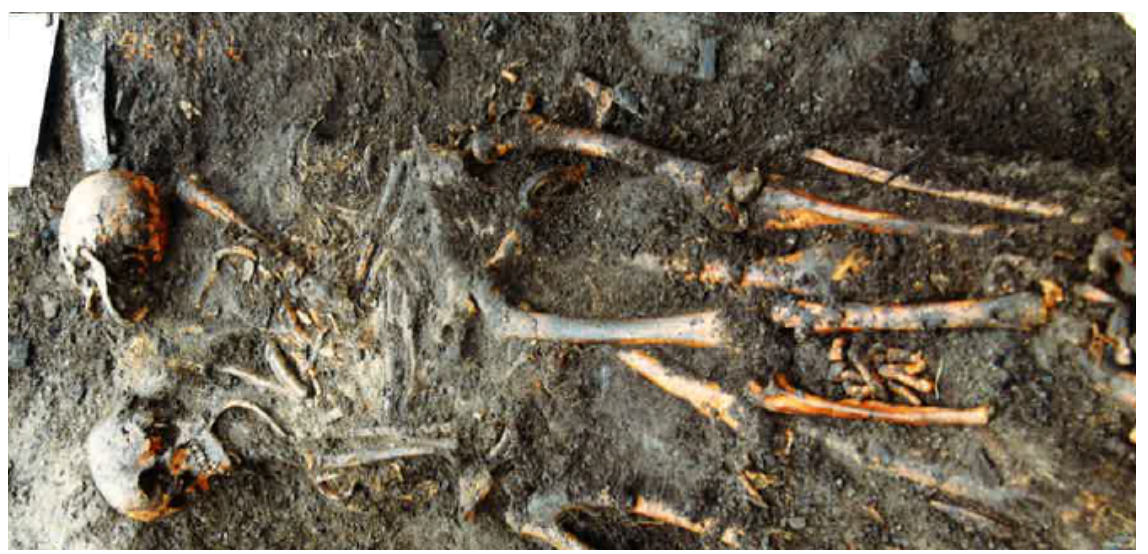

Figure 2. The skeletons and loose bones were lying in two layers. 
but fragmentary. For example, the os coxae were generally missing the pubic bones, and the scapulae and clavicles were also fragmentary. The adults had the majority of the vertebrae present, even though mostly only the arches were preserved. Ribs, hand and foot bones were poorly preserved and commingled and were thus not included in this analysis. All of the individuals were missing the sternum and most of them were missing patellae as well. The remains of children were more fragmentary than the adult remains and many of them included only cranial bones.

\section{Osteological estimation of sex and height}

Sex estimation was done by using morphology of the os coxae and cranium and the measurements of the femoral head. Due to the poor preservation of the pubic bones, the sex estimation was based on the size of the greater sciatic notch [8]. The morphological features used from the cranium included the glabella, supraorbital margins, mastoid process and nuchal crest [8]. In addition, chin shape, gonial angle and mandibular ramus breadth were used in the estimation [9]. The diameter of the femoral head was also used in the sex estimation.

All the long bones (humerus, radius, ulna, femur, tibia, and fibula) were measured with an osteometer. Stature was estimated from lower limb long bone lengths using the equations for North Europeans in Ruff et al. [10]. Combined maximum femoral and tibial length was used whenever possible. If a part of a bone, usually either end, was missing, the original length of the bone was estimated by comparing the bone with a skeleton model [11]. The estimation method was only used for the long bones of adults. The stature of the children could not be determined because the bones were fragmentary or missing.

\section{Estimation of age}

Various osteological and dental methods were used to estimate the age of the individuals. The main methods were based on dentition. Due to poor preservation of some individuals the estimation of age could only be based on very few teeth, in some cases just one tooth. The ages of the children were estimated by using the method of Haavikko [12] and Kataja et al. [13], both of which are based on X-ray analysis. For adults, the methods of Johanson [14] and Solheim [15] were chosen. Both sectioned and un-sectioned teeth were used, according to the methodology.

Depending on the preservation, the age of the children and subadults was also estimated by using epiphyseal union and measurements of the skeletal elements following the standards in Schaefer et al. [16].

For adult age estimation, neither the pubic symphysis nor sternal end of the ribs could be used due to poor preservation of the material. The auricular surface method of Lovejoy et al. [17] was used when possible, but in many instances the surface was too eroded due to taphonomic changes. Even though the cranial suture closure has been found problematic in age estimation [18, 19], the method of Meindl \& Lovejoy [20] was applied. The final assessment of age was based on the information gathered from all the skeletal and dental methods used.

\section{X-ray and macroscopic studies for injuries and diseases}

The skeletons were examined macroscopically for any signs of disease or trauma. In addition, the skeletons were radiographed in the radiology department at Oulu University Hospital. The skulls, jaws and teeth were examined by using skull projections, jaws were examined by panoramic radiographs and loose teeth by intraoral films. Long bones were radiographed using lateral projections.

\section{Dating skeletal remains}

C-14 determination, histological and chemical methods and fluorescence studies were used for dating the remains.

Determination of the C-14 content was done from part of one femoral bone at the Ångström C-14 laboratory, Department of lon Physics, Uppsala University, Sweden, after preparation of the bone samples by the $\mathrm{HCL}$ method [21].

\section{Fluorescence studies}

The femoral or brachial bones of eleven skeletons (skeleton 8 was insufficient for making sections) were sawed transversally on the shaft and 5-mm thick pieces were removed. The sawed surface was exposed to an ultraviolet light lamp, and the presence or lack of fluorescence was recorded [22, 23].

\section{Histological method}

From the femur or brachial bone of eleven skeletons (skeleton 8 was insufficient for making sections), a 5-mm thick cross-section was sawed and fixed in $10 \%$ formalin for 14 days. The samples were then decalcified in $5 \%$ formic acid for 19 to 26 days until softened. Thereafter, they were embedded in paraffin and the $6-\mu \mathrm{m}$ thick sections were stained with haematoxylin eosin [24].

\section{Chemical tests}

Many preliminary screening tests have been widely used in forensic practice in examinations of traces of evidence. Many of them are based on the identification of blood. Such tests include leucomalachite and benzidine tests. Positive results indicate the presence of blood in the sample, which can be used for dating the sample [22, 23]. The tests were performed by dropping the solutions on the bone dust making of eleven skeletons (skeleton 8 had no brachial or femoral bones).

\section{Leucomalachite test}

One gram of leucomalachite in $100 \mathrm{ml}$ of strong acetic acid and $150 \mathrm{ml}$ of distilled water was poured onto the bone, followed by $10 \%$ hydrogen peroxide $\left(\mathrm{H}_{2} \mathrm{O}_{2)}\right.$. A deep green colour reveals the presence of blood $[22,23$, 25].

\section{Benzidine test}

The solution was made by dissolving $0.2 \mathrm{~g}$ benzidin and a small crystal of sodium prusside in $15 \mathrm{ml}$ methanol containing 4 drops of acetic acid. This solution was poured onto the bone followed by a solution containing $50 \mathrm{ml}$ of $3 \% \mathrm{H}_{2} \mathrm{O}_{2}, 100 \mathrm{ml}$ methanol and $50 \mathrm{ml}$ ether. A deep blue colour appears when blood is present $[22,23]$. 
Bones were available as reference material for the histological and chemical tests. According to parish records, the reference bones had been buried 100 to 250 years ago. The bones had been excavated beneath the floor of the Cathedral of Oulu in Oulu, Finland. In addition, a fresh bone control was used.

\section{RESULTS}

\section{Osteological and odontological findings}

The material consisted of the remains of 12 individuals (Table 1). The adult age estimates ranged from 17 to over 50 years of age, whereas the children were approximately $1,4,6$ and 12 years old. The estimated ages of the children were based on dental eruption and development, but also the epiphyseal union was found to support the dental estimates. For individual 2 , the age of approximately 1 year was estimated from the measurements of the pars basilaris [26]. Sex was not estimated for the children.

For seven adult individuals, the sex estimates were based on os coxae. Five of them were estimated to be females (individuals 3, 5, 7, 10 and 12) and two males (individuals 6 and 9). For these individuals, the sex estimations from the pelvis and the femoral head agreed, whereas the cranial morphology was found to be more ambiguous. Individual 14 had only long bones and sex was estimated from the diameter of the femoral head. Based on the diameter, this individual was more likely to be female than male [4].

The stature of two males (individuals 6 and 9) and five females (individuals 3, 5, 7, 10 and 12) were estimated. The estimated stature of the two males was $166.9 \mathrm{~cm}$ and $163.0 \mathrm{~cm}$, whereas that of the females averaged $152.3 \mathrm{~cm}$ (range 147.4-157.8 cm). Stature was not estimated for individual 14 because only the humerus was sufficiently intact for measurements, and stature estimates from upper limb bones are less reliable than those based on the lower limb bones.
In addition to biological profile the pathological conditions were examined. Macroscopic observations were limited due to the poor preservation of the elements. For example, the articular surfaces of the long bones were not always available for examination. Also the vertebral bodies were often absent. The taphonomic erosion had also affected the long bone shafts and observing periosteal lesions was not always possible. Nevertheless, several individuals showed pathological lesions or skeletal abnormalities. Two children (individuals 1 and 2) had slight porosity on the roof of the orbits, which may be diagnosed as cribra orbitalia. Cribra orbitalia has been linked to many possible aetiologies including anaemia and vitamin deficiencies [27]. All the skeletons had multiple signs of enamel hypoplasias in their teeth, which might indicate that the deceased had suffered from chronic and severe malnutrition. The children also had hypoplasias in their primary teeth. The primary dentition begins forming in the uterus and is completed months after birth [28]. The hypoplasias were therefore largely formed during pregnancy.

Several individuals had also carious lesions and calculus on their teeth. Individual 3 showed a well-healed fracture on the left ulna, Schmorl's nodes in thoracic bodies and some degenerative changes in the right knee. The femora of individual 5 are slightly bent laterally (Figure $3 \mathrm{~A}$ ), suggestive of rickets, which used to be quite a common disease resulting from malnutrition. Individual 5 also had a block vertebrae (a failure of separation) of two lumbar spinous processes. These vertebrae were fragmentary but very likely $3^{\text {rd }}$ and $4^{\text {th }}$ lumbars. Individual 6 showed a partial spina bifida occulta. Individual 9 had a shortened femoral neck on the right side. The right femoral head differed from the left head, since it was broad and flat and it was at the same level as the greater trochanter. This usually indicates some type of coxa vara. Coxa vara is a deformity of the femoral neck. It can be either developmental or caused by trauma or other diseases, e.g. rickets [29, 30]. Two individuals (5 and 7) showed healed periosteal lesions on the tibial shaft. Three individuals $(9,10$ and 12) showed Harris lines or growth arrest lines on the $x$-rays of the

Table 1. Results from the skeletal and dental age estimation as well as possible pathology.

\begin{tabular}{|c|c|c|c|c|c|c|}
\hline Individual & Sex & Skeletal age & Dental age & Stature & Pathological conditions & Preservation \\
\hline 1 & - & $11-13$ years & $14.2-15.9 \mathrm{yrs}$ & & LEH, cribra orbitalia & Most major elements \\
\hline 2 & - & 1 year & - & & - & Only cranial fragments \\
\hline 3 & - & 3-5 years & $6.4-6.5 \mathrm{yrs}$ & & Cribra orbitalia & Cranium and long bone shafts \\
\hline 4 & Female & $50+$ & $\begin{array}{c}38-69 \\
\text { yrs }\end{array}$ & 153.0 & Caries, healed fracture, Schmorl's nodes & Most major elements \\
\hline 5 & Female & $30-45$ years & $33-43$ yrs & 149.0 & Caries, block vertebrae, curved femora & Most major elements \\
\hline 6 & Male & $17-23$ years & $\begin{array}{c}15-16 \\
\text { yrs }\end{array}$ & 166.9 & Calculus, LEH?, spina bifida occulta & Most major elements \\
\hline 7 & Female & $35-45$ years & $23.5-42 \mathrm{yrs}$ & 157.8 & Caries & Most major elements \\
\hline 8 & - & - & - & & LEH & Only cranial fragments \\
\hline 9 & Male & $35-45$ years & $\begin{array}{c}36-42 \\
\text { yrs }\end{array}$ & 163.0 & Coxa vara & Most major elements \\
\hline 10 & Female & $30-40$ years & $43-46$ yrs & 154.5 & LEH & Most major elements \\
\hline 11 & Female & $20-30$ years & $23.5-42 \mathrm{yrs}$ & 147.4 & - & Most major elements \\
\hline 12 & Female? & Adult & - & & - & Only long bones \\
\hline
\end{tabular}


femora and/or tibiae (Figure 3B). These lines are generally considered to be associated with disturbances in the growth of long bones due to illnesses or nutritional stress, but other factors may cause them as well [31].

\section{Fluorescence:}

None of the bone cross-sections fluoresced.

\section{Histological results:}

The following observations were made on the bone sections: embrittling of the outer and inner surfaces and the Haversian channels, and the visibility of the endothelium of the vessels. The degree of embrittling of the surfaces varied slightly between the samples, being on average $1 \mathrm{~mm}$. The 100-yearold reference bone was distinctly less embrittled, while the reference bones from the $18^{\text {th }}$ century were more embrittled. Endothelium was found in all samples (Table 2).

\section{Results from the chemical tests:}

The malachite test and benzidine test gave similar results. These tests gave positive reactions on samples from only two skeletons and the fresh control.

\section{C-14 dating}

C-14 dating results gave the radiocarbon years $95 \pm 65 \mathrm{BP}(\mathrm{BP}=$ before present, i.e., before 1950). The radiocarbon years were calibrated by using the OxCal 4.2 program (Bronk Ramsey 2001) and the IntCal13 curve (Reimer et al. 2013). The calibrated years correspond to two time periods: $1670-1780$ $A D$ and $1798-1944$ AD. These results are reported at $95.4 \%$ probability $(2 \sigma)$. (Figure 4).

\section{DISCUSSION}

From a forensic viewpoint it is crucial to decide on the approximate period of burial in order to advise the police as to the need for further investigation. An arbitrary "watershed" of seventy to a hundred years has become generally accepted; less than this, there is a possibility that police investigation is needed, while beyond this, the remains become of interest to medical experts, archaeologists and historians [22, 23].

The macroscopic estimation and knowledge of the history of the village and tar-burning pits allowed the conclusion that the grave in Ruukki

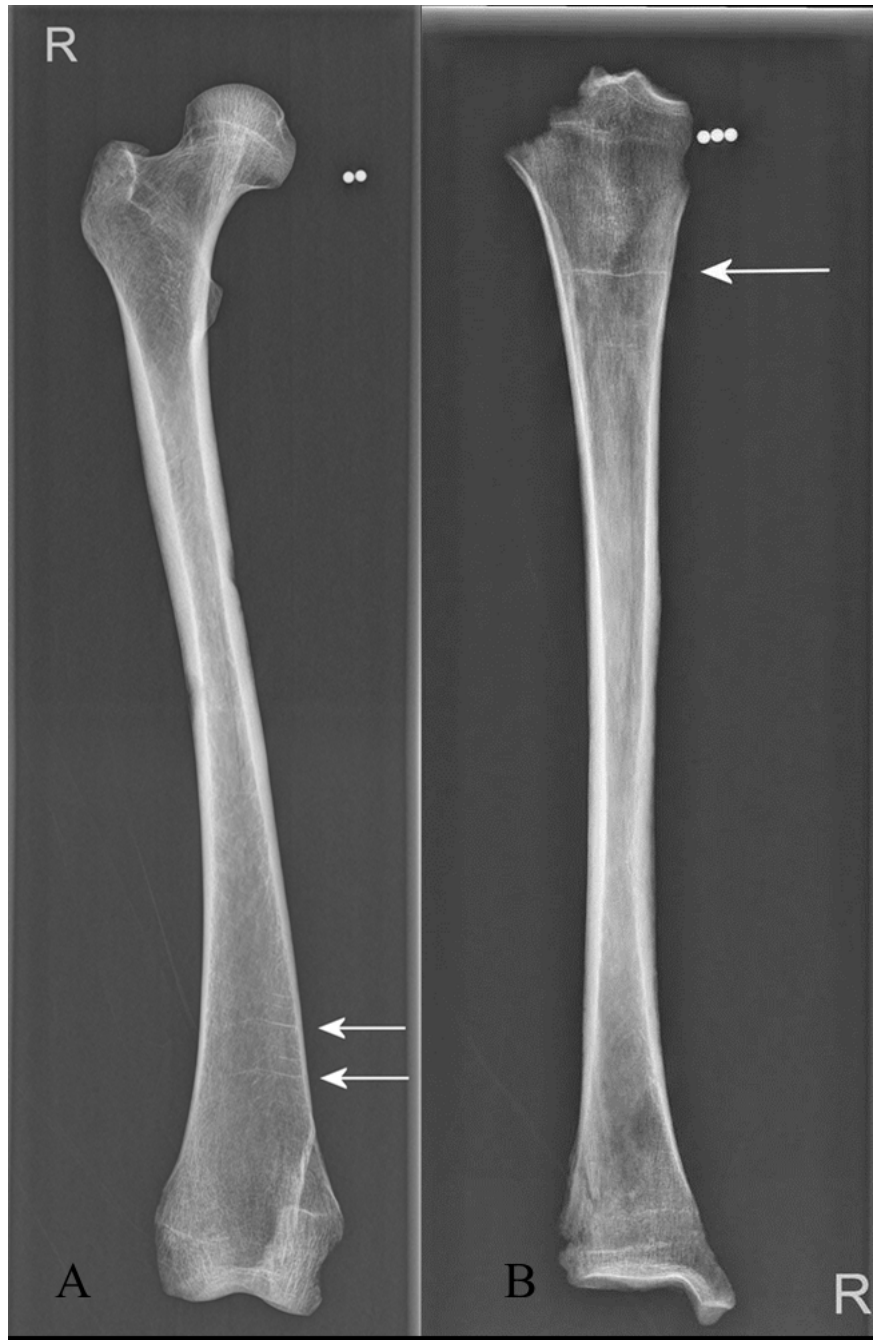

Figure $3 \mathbf{a}$. The radiograph of femur of individual 10. Arrows show Harris lines or growth arrest lines. $\boldsymbol{b}$. Harris lines or growth arrest lines on the $\mathrm{x}$-ray of tibia.

village and the bones were so old that they were no longer of interest to the police, and further investigation of the bones was undertaken by medical experts, archaeologist/anthropologists and historians. With osteological and odontological methods we were able to determine that there were remains of 12 skeletons in the grave situated in an old tar-burning pit in Ruukki village. Of those 8 were adults; 5 females, 2 males and 1 probable female. Four skeletons belonged to children (ages 1-12 years). Other interesting

Table 2. Observations in the histological sections of the bones (the material from skeleton 8 was insufficient for making the sections).

\begin{tabular}{|c|c|c|c|c|c|c|c|c|c|c|c|c|c|c|}
\hline & 1 & 2 & 3 & 4 & 5 & 6 & 7 & 9 & 10 & 11 & 12 & $\begin{array}{l}\text { Fresh } \\
\text { control }\end{array}$ & $\begin{array}{c}\text { 100-year } \\
\text { control }\end{array}$ & $\begin{array}{c}\text { 250-year } \\
\text { control }\end{array}$ \\
\hline Outer surface embrittled & + & + & + & + & + & + & + & + & + & + & ++ & - & + & ++ \\
\hline Inner surface embrittled & + & ++ & + & - & + & - & - & + & - & + & ++ & - & - & ++ \\
\hline Haversian channel embrittled & + & + & + & + & + & + & + & + & - & + & + & - & - & ++ \\
\hline Presence of endothelium & + & + & + & + & + & + & + & + & + & + & + & ++ & + & $(-)$ \\
\hline
\end{tabular}




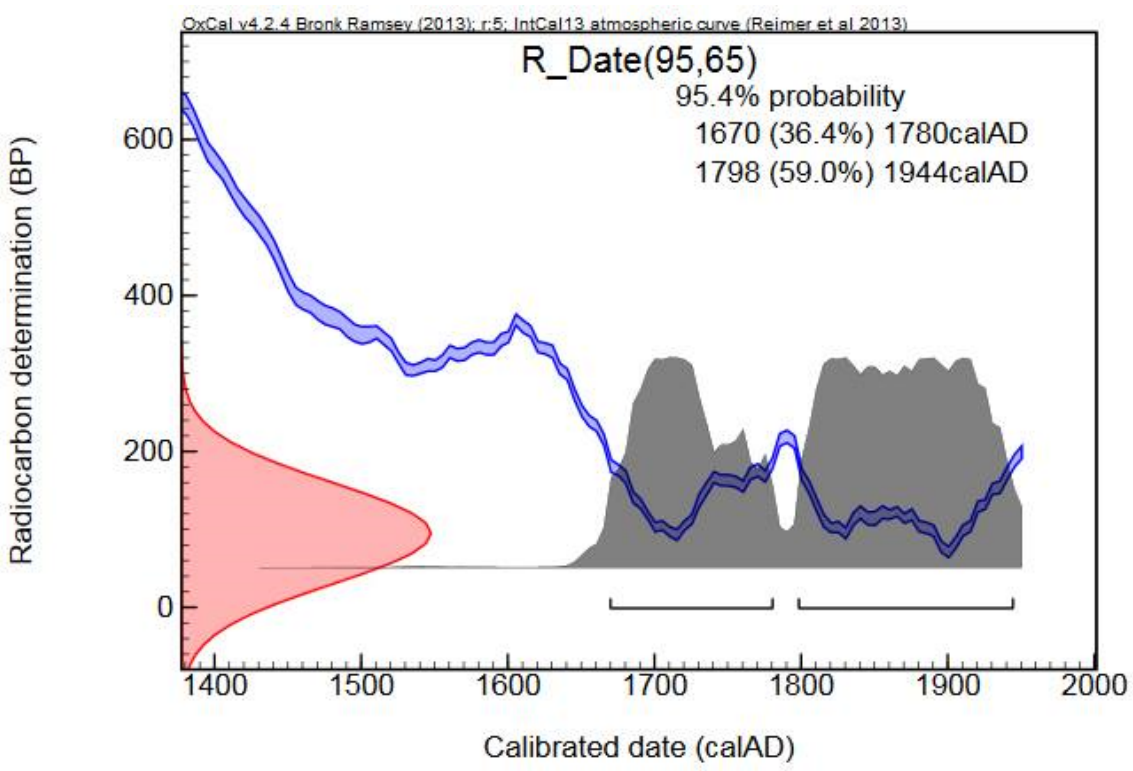

Figure 4. $\mathrm{C}-14$ dating results gave the radiogarbon years $95 \pm 65 \mathrm{BP}(\mathrm{BP}=$ before present, i.e., before 1950).

and important questions still remained: when did these people die, why did they die, what were the causes of death and why were they buried in a tarburning pit?

The bones in the Ruukki grave had largely disintegrated. The surface layer had embrittled by $1 \mathrm{~mm}$ and the softer porous parts of some bones had disappeared [24]. The embrittling of bone surfaces is rather an inexact basis to estimate the decomposition time, although embrittling increases with time in the ground [23]. A rough schedule for these changes is $1 \mathrm{~mm}$ in 100 years in a temperate climate [24]. This degree of softening of the bone surface was observed in Ruukki.

For more exact timing, C-14, histological and chemical tests and fluorescence were used. The material of this study is too recent for C-14 dating, which is seen as great standard deviation ( \pm 65 years). The broad year range is normal for specimens dating from 1670-1950 due to the nature of the calibration curve during this period [32]. The results show with great probability that the remains are younger than from the year 1670 and do not exclude the great famines in the years 1866-1868 and 1696-1697.

The decomposition times of the bones were also estimated by the UV fluorescence and chemical methods, and the results were compared to earlier investigations $[22,23,33]$. The benzidine test has most often been that of choice, but owing to the carsinogenic nature of the reagent, it has been replaced by phenolphthalein [34] and leucomalachite. No reports using the leucomalachite method for determining the decomposition time of bones were available in the literature, but its sensitivity and specificity to detect blood have been studied [25]. This test shows sensitively the presence of human blood, and our results with the leucomalachite and benzidine tests were similar [22]. Fluorescence in a thin section could be demonstrated in the middle part of bones as old as 700 years, which differs from our findings [23]. In the benzidine test on bones with known age, a bone 200 years old was the youngest showing no reaction. The test was made on bone powder, since the test was deemed unreliable when made on bone slices. In the later study, spotty fluorescence was still found in 100-, 500- and 700-year-old bones [23]. The benzidine reaction was positive up to 150 years. Another study on bones between 30 and 3,500 years old indicated that fluorescence was no longer detected in 200- to 350-year-old bones [23]. The benzidine reaction remained positive until 150 years [23]. False positive reactions were thought to be due to iron atoms present in the soil. In this study, the bones were only buried half a meter deep, so that they could have been destroyed by water and ice, for example. This may explain the negative results. The benzidine test gave only one positive result. The histological, chemical and fluorescence tests did not give reliable results for dating. Our results were partly in conflict with earlier findings.

Dating the grave accurately proved to be difficult due to the absence of clothes, jewellery or other belongings, which could have helped in determining a certain time period. Therefore, $\mathrm{C}-14$ dating was performed. After death, the $\mathrm{C}-14$ content of body tissues begins to diminish, thus proving a tool to estimate the time of death. C-14 determination gave a broad year range, which did not help with the dating of the remains.

Historical studies of the $18^{\text {th }}$ and $19^{\text {th }}$ century reveal that mass deaths occurred in Northern Finland during 1696-1697 and 1866-1868 subsequent to famines and concomitant epidemics such as dysentery. According to studies of the history of the geographical area where the grave was found, mortality among the inhabitants was extremely high (3-fold higher than normal) during the decades of the 1830s and 1860s [35]. During these periods, winters were long, lasting until June, and the summers were exceptionally short, with first frosts coming as early as in August. This caused famines in Northern and Eastern Finland. In addition, bacterial epidemics, such as typhus and dysentery, were spreading among the famished population. Groups of poor people left their homes and resorted to begging. These data can explain the mass grave in Ruukki, since it is quite possible that the deceased came originally from another part of the country. The cause of death can be assumed to be inanition and/or infection. It is quite apparent that a burial would be carried out promptly to quench the epidemic, and in such case, the clothes would be burned to prevent the spread of the infection. 
Since the skeletal remains of these individuals showed no evidence of the cause of the death (no signs of violence or fatal diseases), starvation and acute illnesses can be considered as the probable cause of death. These individuals had experienced stressful times already as children. Several of them shoved stress indicators such as linear enamel hypoplasia, cribra orbitalia and Harris lines, all of which are suggestive of periods of disease or nutritional deficiencies during growth.

The use of an old tar-burning pit for the mass burial points to two circumstances present at the time of death. It is possible that the grave was intended to be temporary, awaiting transferal of the bodies to the local cemetery at a more suitable time when the emergency situation had passed, or when the seasonal conditions were more favourable. Another reasonable possibility is that the people had died of some contagious disease and their burial had to be carried out very quickly. Some support for the latter theory is gained from the fact that the deceased had been buried naked, in shallow graves, without coffins, suggesting great hurry, or fear of death. There had apparently been no extra preparations for the burial. In addition to the abovementioned causes of death accidents due to carbon monoxide poisoning, drowning etc. could be possible causes of death.

In summary, the grave had probably been a temporary one, or the burial had been carried out in a hurry. The people had probably died of hunger and concomitant illnesses. We assume that the deaths had happened during the famine between 1866 and 1868, after which the use of tar-burning pit ended. Tar-burning pits were still in use in the $19^{\text {th }}$ century. The use ended in the last half of the $19^{\text {th }}$ century.

\section{ACKNOWLEDGEMENTS}

The authors are grateful for the help they received from the policemen of the Ruukki region in the first phase of the grave investigation. The skilful technical assistance of the laboratory personnel in our departments is also gratefully acknowledged. We also thank Dr Samuli Onnela, Director of the Provincial Archives, for his advice concerning the historical data.

\section{REFERENCES}

[1] Brooks ST \& Suchey JM. Skeletal age determination based on the os pubis: a comparison of the Acsadi-Nemeskeri and Suchey-Brooks methods, Human Evolution. 1990, 5, 227-238

[2] Trotter M \& Gleser GC. Estimation of stature from long bones of American Whites and Negroes, American Journal of Physical Anthropology 1952, 10, 463-514.

[3] Berg GE. Determining the Sex of Unknown Human Skeletal Remains, In: TersigniTarrant MA \& Shirley NR (Eds.), Forensic Anthropology, CRC Press, Boca Raton, 2013.

[4] Spradley MK \& Jantz RL. Sex Estimation in Forensic Anthropology: Skull Versus Postcranial Elements, Journal of Forensic Sciences 2011, 56, 289-295.

[5] Konigsberg L, Holman D. Estimation of age at death from dental emergence and implications for studies of prehistorical somatic growth. In: Hoppa RD, Fitzgerald CM, editors. Human growth in the past: studies from bones and teeth. Cambridge: Cambridge University Press; 1999.

[6] Jellife EFP, Jellife DB. Deciduous dental eruption, nutrition and age assessment. J. Trop. Ped. Env. Child Health 1973, 19, 193-248.

[7] Nawrocki SP. The nature and sources of error in the estimation of age at death from the skeleton, In: Latham KE \& Finnegan M (Eds.), Age Estimation of the Human Skeleton, Charles C. Thomas, Springfield, 2010.

[8] Buikstra J, Ubelaker D (Eds.). Standards for data collection from human skeletal remains, Arkansas Archeological survey research series no. 44, 1994.

[9] Rogers T. Determining the Sex of Human Remains Through Cranial Morphology, Journal of Forensic Sciences 2005; 50: 493-500.

[10] Ruff C.B, Holt B.M, Sladék V, Berner M, Garofalo E, Garvin H.M et al. Stature and body mass estimation from skeletal remains in the European Holocene. Am J. Phys Anthropol. 2013, 148, 601-617.

[11] Forensic Pathology, David Dalimak, Evan Mathes, Emma Lew; forensic Osteology, 563-601, Evan Mathes, Emma Lew.

[12] Haavikko K. Tooth formation age estimated on a few selected teeth. Proc Finn Dent Soc. 1974, 70, 15-19.
[12] Haavikko K. Tooth formation age estimated on a few selected teeth. Proc Finn Dent Soc. 1974, 70, 15-19.

[13] Kataja M, Nyström M, Aine L. Dental maturity standards in Southern Finland. Proc. Finn. Soc. 1989, 85. 187-197.

[14] Johanson G. Age determinations from human teeth. Odontologisk Revy. 1971, 22 suppl. 21. 40-60.

[15] Solheim T. A new method for dental age estimation in adults. Forensic Sci. Intern. 1993, 59, 137-147.

16] Schaefer M, Black S, Scheuer L. Juvenile Osteology, Elsevier, Amsterdam, 2009.

[17] Lovejoy C, Meindl R, Pryzbeck T, Mensforth R. Chronological metamorphosis of the auricular surface of the ilium: A new method for the determination of age at death, American Journal of Physical Anthropology, 1985; 68: 15-28.

[18] Hershkovitz I, Latimer B, Dutour O, Jellema L, Wish-Baratz S, Rothschild C, Rothschild B. Why Do We Fail in Aging the Skull From the Sagittal Suture? American Journal of Physical Anthropology 1997, 103, 392-99.

[19] Wolff K, Vas Z, Sotonyi P, Magyar L. Skeletal age estimation in Hungarian population of known age and sex, Forensic Sci. Int. 2012, 223, 374.e1-8.

[20] Meindl R \& Lovejoy C. Ectocranial suture closure: A revised method for the determination of skeletal age at death based on the lateral-anterior sutures, American Journal of Physical Anthropology 1985: 68: 57-66.

[21] Reimer PJ, Bard E, Bayliss A, Beck JW, Blackwell PG, Bronk Ramsey C et al. IntCal13 and Marine13 Radiocarbon Age Calibration Curves 0-50,000 Years cal BP. Radiocarbon 2013, 55, 1869-1887.

[22] Knight B., Lander I. Methods of dating skeletal remains. Medicine, Science and the law. 1967, 7, 205-209.

[23] Knight B. Methods of dating skeletal remains. Human Biology.1969, 41, 322-341.

[24] Leopold D. Identifikation unbekannter Toter. Interdisziplinäre Methode, forensische Oeteologie. Schmidt-Römhild, Lübeck, 1998.

[25] Vennemann M, Scott G, Curran L, Bittner F, Tobe SS. sensitivity and spesifity of presumptive tests for blood, saliva and semen. Forensic Sci. Med. Pathol. 2014, 10, 69-75. 
[26] Scheuer L, MacLaughlin-Black S. Age estimation from the pars basilaris of the fetal and juvenile occipital bone, International Journal of Osteoarchaeology 1994, 4, 377-80.

[27] Walker P, Bathurst R, Richman R, Gjerdrum T, Andrushko V. The Causes of Porotic Hyperostosis and Cribra Orbitalia: A Reappraisal of the Iron-Deficiency-Anemia Hypothesis, American Journal of Physical Anthropology 2009, 139, 109-125.

[28] Correa-Faria P, Martins-Junior PA, Vieira-Andrage RG, Olivieira-Ferreira F, Marques LS, Ramos-Jorge ML. Developmental defects of enamel in primary teeth: prevalence and associated factors. International Journal of Paediatric Dentistry. 2013, 23, 173-179.

[29] Grissom LE. The Pelvis and Hip: Congenital and developmental conditions, In: Stein-Wexler R, Wootton-Gorges SL \& Ozonoff MB (Eds.), Pediatric Orthopedic Imaging, Springer, New York, 2015.

[30] Mays S, Brickley M, Ives R. Skeletal manifestations of rickets in infants and young children in an historic population from England, American Journal of Physical
Anthropology 2006, 129, 362-374.

[31] Mays S. The Relationship between Harris Lines and other Aspects of Skeletal Development in Adults and Juveniles, Journal of Archaeological Science, 1995 22, 511-20.

[32] Bronk Ramsey C. Development of the radiocarbon calibration program OxCal. Radiocarbon. 2001, 43, 355-363.

[33] Saito S., Tokinava K. Sensitive identification of human blood and simultaneous determination of $A B O$ blood group from a minute blood stain by an Elisa-ABC method. Jap. J. Legal Med. 1992, 46, 483-491.

[34] Cox M. A study of the sensitivity and specificity of four presumptive tests of blood. J. Forensic Sci 1991, 36, 1503-11.

[35] Curran D, Luciuk L, Newby AG., Famines in European economic history: The last great European famines reconsidered, Routledge, 2015 